\title{
Practice and thinking on examination way reform of optoelectronic detection technology course
}

Xue-lian Yu, Jia-cheng Zhang, Tao Shen, Yan-ling Xiong, Wen-long Yang

Xue-lian Yu, Jia-cheng Zhang, Tao Shen, Yan-ling Xiong, Wen-long Yang, "Practice and thinking on examination way reform of optoelectronic detection technology course," Proc. SPIE 10452, 14th Conference on Education and Training in Optics and Photonics: ETOP 2017, 1045254 (16 August 2017); doi: $10.1117 / 12.2269611$

Event: 14th Conference on Education and Training in Optics and Photonics, ETOP 2017, 2017, Hangzhou, China 


\title{
Practice and Thinking on Examination Way Reform of Optoelectronic Detection Technology Course
}

\author{
Yu Xue-lian*, Zhang Jia-cheng, Shen Tao, Xiong Yan-ling, Yang Wen-long \\ Department of Optoelectronic Informational Science and Technology, Harbin University of Science \\ and Technology, West Campus, P.O. Box 130, 150080, Harbin, China
}

\begin{abstract}
Choosing a reasonable examination way is beneficial to the cultivation of high quality talents. Recently, the conventional college examination methods involve writing and oral test, which is extremely focused on academic performance and caused the separation between teachers and examinations. Optoelectronic detection technology is a specialized course with strong applicability. Therefore, we proposed a diverse form and scientific content method. It is proved that the students receive better learning effect and improve learning and engineering practice ability compared with the traditional assessment methods.
\end{abstract}

Keywords: optoelectronic detection technology, examination way, practice, thinking

\section{INTRODUCTION}

The goal of modern higher education is to train and bring up innovative talents with high quality. This goal involves all aspects of education and teaching. The examination of each course is an important part of the teaching process and the most important part of the educational evaluation system. Optoelectronic detection technology is a specialized course for majors of optoelectronic Information Science \& Technology. This course focuses on photoelectric detection system, the light sources and detectors which are used in the photoelectric detection processes. This course includes radiation measurement and photometry, photoelectric sensors, photoelectric detection devices, thermoelectric devices, etc. The important character of this course will be closely cooperating with industry companies. Meanwhile, the students can be trained to achieve an ability of problem-solving and relevant skills on photoelectric detection system. Training students' capabilities on theories and experimental abilities is emphasized in this course. Through this course of study, students can stimulate the research and development of practical optoelectronic detection system or device capacity, and for future research and production to solve the problem of optoelectronic detection technology to lay the foundation ${ }^{1}$. This paper first analyzes the pros and cons of various current test methods of photoelectric detection technology, and then explores a new test method which adapts to this course ${ }^{2-12}$. Through the reform of the examination mode to promote students in the professional courses to actively take the initiative to think about the problem, give full play to their subjective initiative, a solid grasp of professional knowledge, and can effectively prevent cheating. Therefore, it is contributing to the smooth development of high-quality personnel.

\section{THE QUESTION EXIST ON EXAMINATION WAY REFORM OF SPECIALIZED COURSE}

Specialized courses are the courses of professional knowledge which are set up after the basic courses in the University. It is a specialized course for students to engage in a specific field after graduation. And the mastery of professional knowledge of college students has a direct impact on their ability to adapt to the corresponding job as soon as possible. Therefore, in order to urge the university students to study their own professional courses in addition to the ideological improvement of their knowledge, it is also an effective way to reform the corresponding examination methods and mobilize their enthusiasm. In the current reform of education and teaching in colleges and universities, the reform of the examination did not pay enough attention. There are many drawbacks in the existing examination of colleges and universities, which only pay attention to the memory of knowledge and pay attention to inspiration. Criticism of traditional examination methods greatly limits the publicity of students' personality, which is not conducive to the development of independent thinking and creativity ${ }^{2-4}$. It mainly shows as the following:

14th Conference on Education and Training in Optics and Photonics: ETOP 2017, edited by Xu Liu,

Xi-Cheng Zhang, Proc. of SPIE Vol. 10452, 1045254 • ( 2017 ICO, IEEE, OSA, SPIE

CCC code: $0277-786 X / 17 / \$ 18 \cdot$ doi: $10.1117 / 12.2269611$ 


\subsection{Unclear purpose}

Many teachers believe that the purpose of the examination is mainly to give students a course of achievement, and the students think that it is to get the score. That is to say, teachers teach and students learn for the purpose of passing examinations. The scores are given and the teaching task is completed. Because of the lack of effective analysis and feedback on the examination, it cannot play a role in optimizing the teaching content, improving teaching methods and the quality of teaching. The exam manager is concerned with the passing rate of the student, only as a basis for determining whether a student is able to earn credits, rewards, degrees and graduation. The examination manager lacks the effective supervision and the instruction to the exam, and therefore it is difficult to understand the actual teaching effect and the teaching quality deeply.

\subsection{One-sided content}

An exam target is misplaced. Most of the exams focus only on the first three levels of cognitive goals, namely, knowledge, understanding and use of the test, but ignore that of the last three levels, namely, analysis, synthesis and evaluation. There are obvious limitations in the content of the examination, and the examination content is mostly knowledge-oriented, the lack of comprehensive ability and quality evaluation of students.

\subsection{Not fully functioning}

At present, the efficiency of test questions is not high. Most of the course examination is completed once, and it is difficult to accurately evaluate the actual learning situation and level. At the same time, the examination is regarded as the conclusion of the course, and its feedback function is not taken seriously. Therefore, the examination does not play a role in promoting the teaching content, methods and teaching quality, and it is difficult to correctly play the guiding role of the examination. In addition, the functions such as the prediction, discrimination and evaluation of college examination have not been properly and effectively implemented.

\subsection{Single way}

Through years of teaching and teaching management experience accumulation and investigation, we believe that the current curriculum examination system is the key to the problem. The current curriculum examination system focuses on the organization of the process and the evaluation of student test scores, and is "a test success" model, ignoring the test results of the feedback. Most of the required courses to take closed-end written examination of the way examinations, elective courses are mostly open-book or course papers way exam. There are many exams, there are more than one test, practice, ability to study less; unified examination and more, there are many exams, Less than the law applies. This form of test to curb the individual development of students, ignoring the needs of students personalized development and creativity. Test coverage is narrow, poor quality, objective questions, less subjective questions, questions are not updated in time. It is not conducive to exert the initiative and individuality specialty, which is not conducive to the "students 'application" for the students' characteristics.

\subsection{More serious unfair phenomenon harm the mental health and moral quality of College Students}

Because of various reasons, the false impression and feelings, likes and dislikes grading, leads to unfair phenomenon of human, has a negative effect on the students and seriously affected the normal education and teaching activities, the bad style of study and examination. Mechanical test content and method will not only lead to the phenomenon of cheating repeated but also make the students to exam the boredom, fear, can easily lead to the acquisition of students' sense of powerlessness, and seriously affect the students' learning and life. Therefore, the students' psychological health and moral quality caused serious damage and even affect people's life.

Vigorously promoting the reform of examination has become an urgent task to further deepen the reform of teaching in Colleges and universities.

\section{SOME SUGGESTIONS ON THE IMPLEMENTATION OF THE COURSE EXAMINATION OF OPTOELECTRONIC DETECTION TECHNOLOGY}

In order to give full play to the role of examination in education teaching, personnel training, guiding, and reflect the relevance, effectiveness and creativity of teaching, the examination method of photoelectric detection technology course for optoelectronic information science and engineering professional in our college broke the original mode. Aiming at the problems in the examination, we take a variety of diverse procedural assessment methods. We are fully aware that its aim is not only to test the knowledge but also to test the ability of students to use knowledge, practical ability to operate, 
teaching participation, etc. According to the different teaching objectives and the different requirements of students, different courses should adopt different assessment methods, or integrate application of several different ways. Therefore, a series of reform measures have been adopted.

\subsection{Set up the examination concept of job quality test}

With the advancement of quality education, we must construct the examination evaluation system which is suitable for higher education and improve the students' ability including using knowledge, self-study ability, practical ability, selfevaluation ability, analyzing and solving problem through the guiding role of examination Wait. We are fully aware that the purpose of the examination is not only to assess the student's academic performance but also adjust the teaching progress and content and improve teaching methods through the feedback. Thus the quality of teaching is bound to be greatly improved. Examination can also detect the development level of the quality of different individual students.

\subsection{The establishment of outstanding higher education characteristics of the assessment model}

The evaluation of higher education should adhere to the principle of comprehensive ability. And the knowledge and skills should be paid equal attention. The ability and skills assessment can be seen as the main line of the principle and abandon the only way to examine the ability of students to review the endorsement. The examination plays a role of the display, the feedback function and the guidance in the teaching activity. Therefore, we set up the procedural examination mode of "examination form suitable to the teaching content and ability training" the of optoelectronic detection technology courses. Table 1 gives the classifications of procedural assessment methods and their fractional number in the total score.

Table 1 The classifications of diverse procedural assessment methods and their fractional number in the total score of 100

\begin{tabular}{|ccc|}
\hline Assessment methods & Classification & Fractional number \\
& Attendance rate & 5 \\
& Homework & 5 \\
Usual grades & Classroom interaction & 5 \\
& Daily test & 5 \\
& Experimental operation & 3 \\
Experimental results & Experimental report & 7 \\
& Hands-on operation & 6 \\
Course design & Course papers & 14 \\
& Topic & 3 \\
Flipped classroom & Classroom performance & 7 \\
& Oral test & 10 \\
Final exam & Written test & 30 \\
\hline
\end{tabular}

(1) Pay attention to the diverse procedural grades

In order to improve the quality of students' learning and reduce their stress at the end of the study, the procedural assessment system is implemented. That is to say, the students usually can account for $60 \%$ of the total score (usual grades, experimental results, course design, flipped classroom, etc). This approach can be avoided mainly by the final exam to determine the drawbacks of academic performance, and encourage students to use martial arts in the usual rather than the end of the assault. This is conducive to the construction of style of study.

(2) Diversification of diverse assessment methods

The form of assessment is based on the nature and characteristics of the course. This course mainly includes the following classification: attendance rate, classroom interaction, daily test, homework, experimental operation, experimental report, hands-on operation, course papers, etc. It focuses on examining the students' ability to use knowledge and manipulating skills, and implementing modular assessment. Usual grades module mainly includes attendance rate, classroom interaction, daily test, homework. The theoretical module is mainly composed of closed-book, open-book examination, paper and defense, case analysis, investigation report and other forms; Skills module to process- 
based assessment, or the use of experimental design, curriculum design, the actual creation, hands-on operation, simulation projects and flipped classroom. A comprehensive result is considered to the process of students to participate in learning and peacetime results, and make the assessment of diversification. So it is a more comprehensive examination of a student's academic performance.

(3) Focus on feedback mechanisms

The end of the exam is not the end of the course. Through the examination, students can find themselves in the study of the problems. Through the analysis of examination results, teachers can find out the situation of the students in the knowledge system, the use of knowledge, practical ability, language expression ability, comprehensive quality. Thus the prediction and diagnosis function of the test can be realized. Teachers should analyze the results of the examination and communicate with the students so that teachers and students can benefit from it.

\section{EVIDENCE OF PRACTICAL EFFECT OF EXAMINATION REFORM}

Since our examination method of optoelectronic detection technology course has broken through the original model and a wide range of assessment model is adopted. Namely, the total score has been divided into a number of assessment items. Therefore learning process has always been interspersed with the assessment process assessment method. Fig .1 gives the number of student for different scores section before and after reform in 2016 year. As shown in Fig.1, the total score is evidently improved. The students' attention degree to the course study was significantly improved, therefore students concerned about every detail of the course in order to improve students' learning ability by theirselves. At the same time, the classroom time utilization is significantly improved so that students can achieve efficient learning.

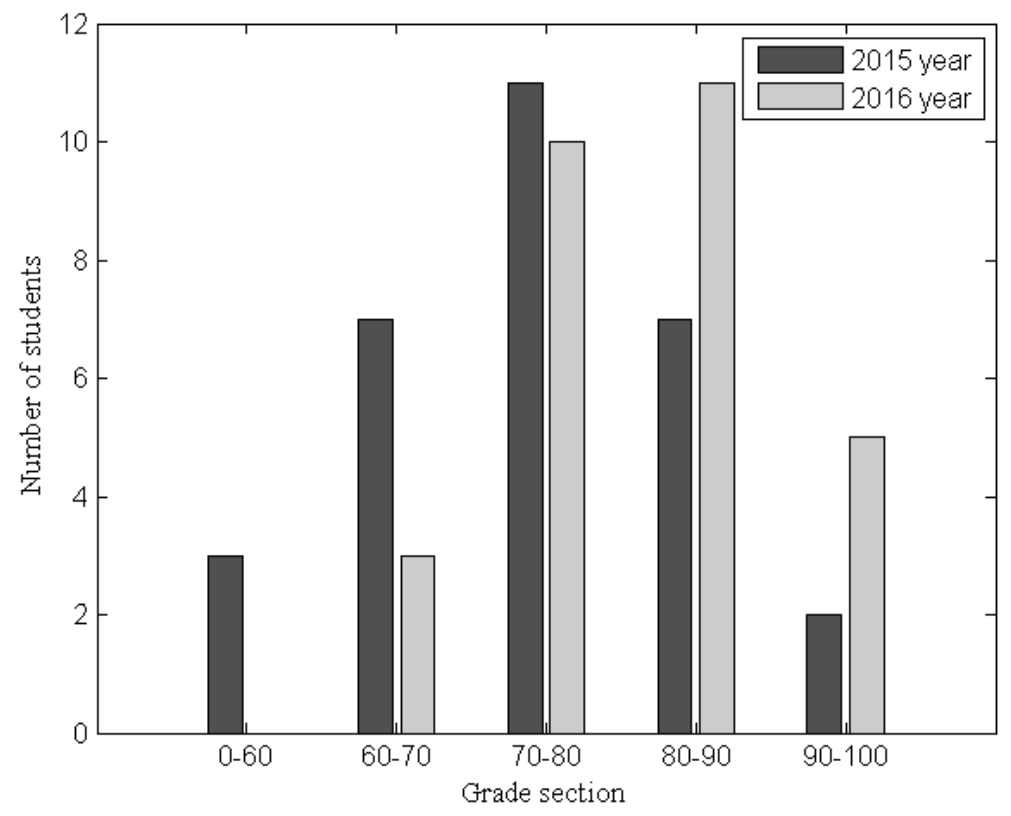

Fig .1 The number of student for different scores section before and after reform in 2016 year

Student class questions and homework scores were significantly higher than the previous, indicating that the process of assessment of the students usually does a good job to promote the role of learning. Oral and practice together, each project in addition to the completion of the corresponding real operations, but also to answer the relevant questions. That is to say, the contents of the oral test questions and practical operations have a certain connection: As students usually pay attention to this course, in addition to significantly improved practical ability, and practical exercises related to the degree of mastery of knowledge is also significantly improved: The original report was replaced with a sample report, requiring the student to complete the corresponding sample report in the laboratory after each experiment. So students are particularly hard when the experiment, and always pay attention to the work of the series proposed a series of questions, in a timely manner to ask the instructor. In addition, the proportion of theoretical assessment in the total score 
reduction, usually check and practice assessment in the proportion of the total increase in the score, but also clear the importance of learning attitude and the importance of practical skills.

\section{CONCLUSION}

The reform of professional course examination is inseparable from the teaching reform of the course. It is an important part of the latter, and the two are interrelated and mutually included. The teaching reform of the course is the teaching content, teaching methods, teaching materials and other aspects of the reform. It is bound to involve the reform of the examination mode, requiring the examination mode to serve the teaching reform. In turn, the reform of the examination will certainly deepen the reform of teaching. And then the students' learning is achieved into a virtuous circle and the comprehensive development of students is also promoted. Optoelectronic detection technology course are the theory and practice, the medium of basic applied courses for the majoring students. It realized the practical, continuation and development of knowledge besides teaching knowledge. Therefore, the diversification of the assessment method is adapt to the higher education teaching a better assessment model, the " diverse procedural assessment " concept and curriculum assessment project settings for all higher education courses have a good reference.

\section{ACKNOWLEDGEMENT}

Key education teaching research project of Harbin University of Science and Technology: The innovation and practice of the course design of the course of " Optoelectronic information science and Engineering" (220140028); Heilongiiang province education scientific planning priority subject in 2015: Cooperative education mode optic-electric information professional study and practice of new academic tutorial system (GJB1215035); Special education teaching research project of Harbin University of Science and Technology: "Network+" optic-electric innovation practice curriculum construction (120150005).

\section{REFERENCES}

[1] Zhao, X. Y., "Exploration and practice of teaching specialized courses for photoelectric information majors." China science and technology information. Papers 3: 246-248 (2010).

[2] Wang, Y. L., "Reform and innovation of curriculum examination for cultivating applied talents." Education and Vocation. Papers 20: 20-22 (2010).

[3] Li, Y. P., "Talking about the examination mode of specialized courses in colleges and universities." Journal of Shanxi University of Finance and Economics (Higher Education Edition). Papers 12 (2): 1 (2009).

[4] Wang, K. P., Zhang, Z. G., Cheng, L. F., "An attempt to reform the examination mode of professional course for engineering students." Education Teaching Forum. Papers 28: 66-67 (2012).

[5] Wang, F., "Discussion on the mode of examination in information teaching." DA ZHONG KE JI. Papers 1: 159-160 (2009).

[6] Zheng, J. X., Tian, Y. H., "An analysis of the mode and the advantages and disadvantages of university." China Electric Power Education. Papers 138: 109-110 (2009).

[7] Zheng, G. H., "The new attempt to reform the curriculum examinations." Henan Education (Higher Education Edition). Papers 9: 56-57 (2007).

[8] Guo, J. J., Yang, Z. J., Yang, X. D., "Discussion on the reform of examination mode and examination management in college." Education Teaching Forum. Papers 35: 188-189 (2011).

[9] Yuan, W. X., "Rational thinking on the design and implementation of research course." Journal of the Chinese Society of Education. Papers 2: 29-31 (2000).

[10] Cao, Z. P., "Examination analysis and teaching reflection: take a course as an example." University Education Science. Papers 2: 38-42 (2004). 
[11] Zhao, X. K., Shen, Z. M., Yan, C. H., Chen, Q., "Discussion on the reform of professional curriculum examination." Journal of Chengdu University of Technology (Social Sciences). Papers 11 (1): $95-97$ (2003).

[12] Gao, L., "Reform of curriculum examination and construction of innovative talents training model." Journal of Shenyang Normal University (Social Science Edition). Papers 33 (1): 35-37 (2009). 